\title{
Sense of place as an indicator of community sustainability
}

\author{
by Richard C. Stedman ${ }^{1}$
}

\begin{abstract}
"Sense of place," or the meaning and attachments that community residents have towards their community, is a potentially useful and somewhat neglected indicator of sustainability. Issues of human community need to be addressed in forest management. Recent considerations of forests as complex ecological systems to be sustained have tended to neglect human concerns. These include, but are not limited to, economic well-being: other "subjective" indicators of quality of life are also relevant, and comprehensible via conventional scientific inquiry. Sense of place is one such indicator - although quantitative research on sense of place is in its infancy, it is readily understood through conventional social psychological measures, which have the advantage of being monitored over time or compared across settings.
\end{abstract}

Key words: sense of place, social indicators, community wellbeing
«Le sentiment d'appartenance », ou la signification et l'attachement que les résidents d'une communauté accordent à cette dernière, représente un indicateur potentiellement utile et jusqu'à un certain point négligé de la durabilité. Les questions des besoins humains doivent être étudiées en aménagement forestier. Les considérations récentes entourant les forêts en tant que systèmes écologiques complexes qui doivent être durables ont eu tendance à négliger les besoins humains. Parmi ceux-ci on retrouve, mais non seulement celui-ci, le bien-être économique: d'autres indicateurs « subjectifs » de la qualité de vie sont également significatifs, et peuvent être étudiés au cours d'une enquête scientifique conventionnelle. Le sentiment d'appartenance est l'un de ces indicateurs - même si la recherche quantitative sur le sentiment d'appartenance n'est qu'au premier stade, et il est évalué au moyen des mesures conventionnelles de psychologie sociale qui ont l'avantage d'être étudiées en fonction du temps ou comparées pour toute la population étudiée.

Mots-clés: sentiment d'appartenance, indicateurs sociaux, bienêtre communautaire

notes that the Brundtland definition is overly broad and is attractive in part because hard choices are disguised - should human development (i.e., economic expansion) be emphasized or sustainable environments? Sustainability is not neutral; one must recognize that any given strategy will always favour some interests over others. This forces con-

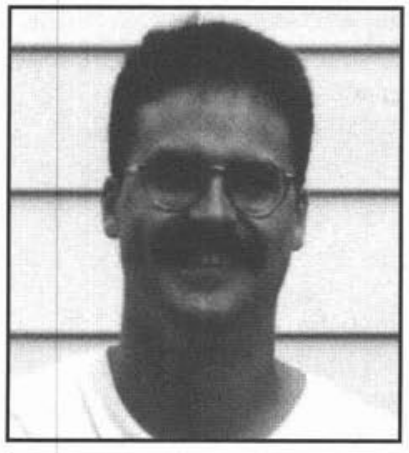
scious consideration of tradeoffs - what things do we want to sustain and why? Answers to this question typically fall according to disciplinary boundaries. There have been three primary disciplinary emphases: economists emphasize the maintenance and improvement of economic well-being while maintaining stocks of natural capital, ecological definitions emphasize the preservation of biological/ecological systems, and sociocultural emphases seek to preserve social/cultural systems, noting that what counts as costs and benefits value is ultimately determined by societal values.

\section{Difficulties with the Sustainability Concept Sustainability is Vague and Potentially Contradictory}

Sustainability is an attractive concept in part because it does not appear to force choices between economic development and environmental protection (e.g., Munasinghe and McNeely 1995). Sustainability seems "reasonable," offering a middle ground solution between outright extraction and complete preservation of natural resources (Johnson 1993). However, Rees (1997)

\footnotetext{
${ }^{1}$ Canadian Forest Service, Northern Forestry Centre, Edmonton, Alberta.
}

\section{What Place do Humans Have?}

Munasinghe and Shearer (1995) note that "social issues become important when determining what is to be sustained, for how long, and in what manner ... who is to benefit, and how the benefits will be distributed." Sustainability involves interactions between biophysical, economic, social, cultural, and political systems, nearly always with tradeoffs between objectives; although these are social issues, the authors assert that sustainability is ultimately not a social matter (social sustainabilty cannot be achieved if biogeochemical limits are reached).

Others disagree, suggesting that sustainability is ultimately a social construct. For example, Audriac (1997) notes that 
not only do definitions of sustainability vary by interest group, the term itself is inherently political. All definitions are rooted in a critique of industrialism. Sustainability is, therefore, a shorthand for "... commitment to ecology — sustainable agriculture, sustainable economics, sustainable forestry, sustainable communities, and sustainable development refer to the specific discipline or intellectual domain under the transformational influence of the emerging ecological worldview" (Audriac 1997). Thus, rather than being separate (and potentially competing) domains, the author suggests that arguments between these domains are a product of them being at different points on the same continuum (the degree to which they critique the modern industrial worldview), rather than being essentially different critiques).

\section{Sustainability is Difficult to Measure}

Given the range of elements of sustainability, it is not surprising that many objections have been raised with respect to its measurement (see Carpenter 1995 for an annotated bibliography). For example, sustainability is difficult to measure because of the large ratio of noise to signal; this is not always understood by policymakers who have come to assume a high degree of certainty in science. Munasinghe and Shearer (1995) note that concepts such as ecological capital are difficult to define because of space and scale - at what level of scale ought sustainability to be measured? Rees (1997) recognizes that the spatial aspect of sustainability is often hidden because places interact with each other. For example, economic trade between areas can obscure sustainability - one community may be prosperous while the environmental effects of its standard of living accrue elsewhere. This is true for time-based relationships as well - there may be lag effects that obscure the relationship between related phenomena.

\section{Sustainabilty of Forest Communities - What Should Forests Sustain?}

Despite the complexity and difficulty in measuring sustainability, it is a potentially useful tool in thinking about forest-dependent communities. It directly engages the relationships, so prevalent in the literature and in the communities themselves, between human well-being and environmental protection. The remainder of this paper is dedicated to explicating two questions: "what should forests sustain," (see Gale and Cordray 1994) and "what measures shall we use?" I suggest that human well-being is a critical component of any definition of sustainable forestry, and it should not be measured solely by traditional means of secondary analysis of socio-economic indicators. Rather, subjective indicators of sustainability need to be incorporated as well.

\section{Forests as Providing a Sustained Yield of Timber}

Initial attempts at rationalization of resource management (in response to rapid overharvest) emphasized an agricultural model of forest practices, or sustained yield of resources. Under this paradigm, forest management emphasizes benefits provided to humans - forests should yield a steady stream of economically valuable products. These views of forests, therefore, explicitly incorporate humans, including the needs of the local community. Hibbard and Elias (1993) note that United States Federal timber management has assumed that sustained-yield approaches to timber harvest foster community sustainability. The initial instability of "timber mining" was linked to social malaise, as an unemployed transient workforce prevents the development of stable communities. To transform from timber mining to "timber culture," managers must achieve continuous production, and provide permanent employment spatially near the community. For example "working circles," where the harvest steadily pivots around a central community, allow the timber cutter to sleep at home and establish a family life, and hence establish stable forest communities (MacKaye 1919).

The primary beneficiary from sustained yield approaches is very often the forest products industry, rather than the local community. History has demonstrated that community sustainability is not necessarily achieved by a steady timber supply - if labour is replaced with capital, unemployment and displacement can occur even if the amount of timber being processed does not decrease (Kusel 1996). Common to this view, however, is that the forest exists primarily to sustain human needs, whether the community, the corporation, or the consumer.

\section{Forests as Sustaining Ecological Communities}

Sustained yield forestry as described above has been criticized for an overly narrow focus on forests as little more than tree farms subservient to human needs. The "ecological community" view of forest sustainability stands in stark contrast. Forests are complex ecological interdependent communities. Franklin (1995) notes that “...the concept of sustainability in forestry has often been narrow and limited to continued production of wood fibre." Aplet et al. (1993) assert that forest research/management must be expanded beyond an agricultural model of commodity production to an ecosystem approach that maintains ecological integrity. Although some components have economic value and others do not, all are important to the forest ecosystem. Rivlin (1993) suggests the necessity of an expanded notion of forest value - forests do not just support wood production, but a wide variety of goods and services such as climate, beauty and habitat. To maintain these diverse values, forests cannot be managed as tree farms. Sustaining forests thus requires sustaining this broader range of values, goods, and services.

Humans and their needs are typically excluded from this ecological systems view of forests. In short, the needs of people interfere with sustainable ecological management. In a telling passage, Aplet et al. (1993) assert that “... once we have the science of ecosystem management well in hand, we still have to address an array of social, economic, political, and institutional factors that will profoundly affect our ability to implement an ecologically sound approach to forest management." Sample (1993) somewhat wistfully notes that "Once we have ... developed the scientific understanding of ecosystem functioning and response necessary to achieve desired resource conditions, we must still confront a host of social, political, and economic barriers to the implementation of these changes." These authors clearly believe that human needs are external, or problems to be dealt with, rather than integrated into the ecosystem concept. In this "public relations" approach to dealing with public concerns, the ecosystem approach needs to be socially responsible only insofar that the public will support (or at least accept) the judgements of scientists and managers.

The ecological view of forests as described above is often touted as expanding the notion of forests from simple tree farms 
to more complex systems that offer a variety of human and nonhuman products and services. The realization of ecological complexity has been achieved, however, only at the expense of excluding humans from the system, as "barriers" to good management rather than as integral components of it. How interesting that this "expanded" view of forests and forestry actually is, therefore, a step "backward" in one respect, by negating the role of human community as part of forest systems. Truly sustainable forests ought to play a role in sustaining human communities. I am not advocating a return to subjugating the needs of the forest ecosystem to the needs of the human community. Nor are economic interests the only thing that forests ought to sustain. However, human interests should not be placed outside of the forest ecosystem - human poverty (economic or otherwise) in the midst of natural capital wealth does not suggest sustainability. Therefore, this paper attempts to tread the "middle ground" that seeks the maintenance of environmental quality and human quality of life as well.

\section{Approaches to Understanding Community Sustainability \\ Sustainability and Socio-economic Indicators of Well- being}

The question that the remainder of the paper seeks to answer is how we decide whether human community is being sustained - what should we take as reliable and valid indicators of sustainability? Community sustainability entails more than economic well-being. Among those concerned with sustainability, Toman (1992) suggests that economists primarily focus on the maintenance and improvement of human living standards. This reflects a narrow definition of living standards; there are other non-economic indices/indicators of social well-being to take into account. Economic measures such as per capita income need to be considered as just one indicator among a set of indicators of sustainability or quality of life.

Fisher and Liebl (1997) specifically assert the utility of using a social indicators approach to assess community sustainability. But what to measure? Andrews and Withey (1976) suggest that ideal indicators ought to provide time series data over an extended period of time, be relevant to policy, be a limited set - not so much detail to prevent communication, but comprehensive (cover all facets of society), and disaggregable to the most relevant spatial unit of analysis. They should also address most of the relevant concerns of the population of study, and be measurable statistically. The authors also make the distinction between "objective" and "subjective" indicators of quality of life, with objective indicators researcher-defined measures or products of the accounting or record-keeping of institutions and agencies, such as the United States Census or Statistics Canada. Subjective indicators are those that reflect the input and needs of the community.

The most common type of study that has attempted to answer this question for forest communities examines the relationship between forest dependence (as measured by the proportion of jobs that are in forest-related industries) and researcher-defined indicators of socio-economic well-being (e.g., Drielsma 1984, Howze et al. 1993, Overdevest and Green 1994). Interestingly, the need to separate economic outcomes from quality of life is not a new critique to research in forestry: Kusel (1996) notes that some of the earliest research on forest-dependent communities (e.g., Kaufman and Kaufman 1946) recognized that there was more to well-being than economic prosperity. Most studies are dominated by economic indicators, such as poverty and unemployment rates, but include some other measures of well-being, such as arrest rates, age dependency ratios, and high school graduation rates. Much of this research suggests this relationship is negative - i.e., places that are characterized by a high degree of dependence on timber have lower levels of socioeconomic wellbeing (see Heberlein et al. 1994 for a meta analysis of this relationship).

Many studies of forest-dependent communities, such as those cited above, have used researcher-defined indicators. In many cases, indicators fail to live up to the criteria suggested above, especially in the domains of relevance to the local community. Kusel and Fortmann (1991) note that conventional sociodemographic indicators of well-being, although usually seen as "more objective," have numerous limitations. They ignore structural conditions, institutional arrangements such as the concentration of capital and land ownership; looking at "average" socio-economic well-being can hide a great deal of inequality (at the community level or even at smaller levels, such as within families); and material well-being is not necessarily a good indicator of quality of life. In the United States, the most comprehensive data are available only at the county level, leading researchers to focus analysis at this level, despite criticisms (e.g., Kusel 1996) that this level of analysis poorly reflects community concerns and can hide a great deal of variation.

\section{The Role of Subjective Indicators}

Critiques of objective indicators such as those levied above have led a few researchers (Andrews and Withby 1976, Kusel and Fortmann 1991) to advocate research designs that make use of subjective indicators of social well-being that are rooted in the interests of the community, rather than defined by an outside researcher. Andrews and Withey (1976) note that "since it is widely agreed that the notion of quality of life includes important perceptual and subjective elements, there is need for indicators that reflect these elements as well ..." Fundamentally, subjective indicators emphasize people's perceptions of their own well-being; its dimensions, the factors that influence it, and the consequences of different levels of it.

Subjective indicators have the advantages of relevance, reflexivity, and depth of understanding of the workings of a particular rural community. However, these types of measures have problems of their own. They typically are weakly related to sociodemographic measures (Campbell 1981, Moum 1988), with little understanding of the source of this divergence. Sen (1984) adds that such measures, as they are fully based on the mental state of an individual, can result in "physical condition neglect," where phenomena that the individual does not notice do not make a difference to their quality of life. Rivlin (1993) adds that sustainability efforts have been hampered because "political decision process emphasizes benefits that can be identified, measured, appropriated, and valued in monetary terms. The process tends to neglect diffused social benefits that cannot be easily valued or even measured, such as the benefits of clean air, wildlife habitat, or scenic beauty."

Subjective measures are typically equated with qualitative research methods such as focus groups or participant obser- 
vation. Although most of the research assessing subjective measures has been qualitative, the de facto suggestion that "subjective" means "unmeasurable using statistics" is not necessary and may weaken the position of subjective measures when such results differ from objective measures (Campbell and Converse 1972, Bateson 1972). Andrews and Withey (1976) suggest that locally defined issues can be systematically measured, monitored over time, and compared between subgroups. I agree with this position. Questions about the subjective internal states of individuals can be asked by researchers - "how would you rate your quality of life, what are the best aspects, what are the worst?"

\section{Sense of Place as a Quantitative and Subjective Indicator of Sustainability}

Above all, forest communities should be sustained as viable "places," based on the maintenance of natural capital and human well-being. I assert that the associated sense of place is quantifiable and yet subjective in that it reflects the perspectives of community residents. Sense of place concerns are often articulated in debates about preserving personal and community identity in the face of social or environmental change. There is an economic well-being component to these arguments, but they extend well beyond to include other quality of life concerns "this is a timber town," or "logging is a way of life that is under threat." These concerns suggest that the sense of place of forest-dependent communities is perhaps itself an object worthy of sustaining. Kusel (1996) provides support for this position: "As a landscape, sacred place, or resource, the forest supports local residents and contributes to the definition they have of themselves and their understanding of who they are. The lifeways of community members and the landscape are intertwined. Thus, when discussing dependence, one must recognize that the forest provides not only the means of production, diversely defined, but sustenance to the local living tradition ..." Under this framework, to a logging community the dollars generated via tourism (for example) may not be equivalent to that based on harvesting or processing timber.

These statements suggest the viability of forest communities as "places" as a potentially important aspect of their sustainability. Sense of place is the meaning attached to a spatial setting (in this case, the community) by a person or group. As with other subjective measures, research on sense of place has been dominated by in-depth, qualitative analyses of a particular group in a particular setting (i.e., case studies) that have not typically produced results that build systematic knowledge that can be compared across settings, stakeholders, or resource policy regimes. I have argued (Stedman 1997) that if sense of place concerns are to enter the debate as elements of sustainability, they need to be more systematized and considered quantitatively. Recent research (Jorgensen and Stedman 1999) has begun to measure sense of place via conventional environmental social psychology theory as an attitude towards a spatial setting (such as one's community). Mercifully setting aside the range of definitions of attitude, most agree that (at minimum) attitudes are overall evaluative (good/bad) statements that also have a cognitive (descriptive beliefs) component.

Viable measures of sense of place as an attitude towards one's community (as an indicator of community sustainability) should contain, at minimum (1) a series of items designed to measure overall evaluation as "quality of life" (e.g., this community is my favorite place to be), (2) descriptive beliefs or place meanings (e.g., this community is a logging town), and (3) evaluative beliefs that allow examining the factors that best predict the overall attitude measures (e.g., there are too many tourists in this community). Under this view, sustainable communities are those that are typified by high levels of expressed quality of life. However, the overall attitude as an aggregated indicator of well-being is insufficient to understand sustainability (just as overall measures of biophysical sustainability are too general). It is crucial to understand the structure, the components of satisfaction and quality - what are the place meanings that people hold, and how does each contribute to overall satisfaction? For example, do people who believe that their community is a "timber town" evaluate it more or less positively than people who believe that it is a "tourist town?" How are these beliefs and attitudes distributed throughout the community? What are they related to - e.g., do new residents of the community differ from long term residents?

The sense of place approach described above bridges the gap between objective and subjective indicators of community well-being. The aggregate measures derived from the approach should be systematically comparable between different stakeholder groups in the community. Comparable aggregate measures also allow comparisons between communities, to observe, for example, whether two communities that have similar natural resource bases but different management strategies (e.g., wilderness designation versus high levels of timber harvest) show different patterns of community satisfaction. The disadvantages often levied at these quantitative approaches (that they do not reflect local concerns) can be ameliorated by field work that inventories the community issues, making sure that their full range is reflected by the survey items.

\section{Cautions and Caveats}

Measuring community sustainability via sense of place theory is not without complications. This section of the paper outlines some of the difficulties in measuring sense of place and how they can be dealt with.

\section{Meanings are Contested: Community Stability or Resilience?}

Sense of place entails multiple meanings (e.g., Grieder and Garkovich 1994) or beliefs about the community. These will vary among community residents and visitors - the forest community may represent a place where economic livelihoods should be made, a storehouse of resources for human uses, a place with a pristine environment, or a place where visitors and newcomers should be welcomed. Each of these meanings may be associated with strong positive attitudes towards the community. One cannot easily sustain sense of place if opinions about what is to be sustained differ dramatically between community interests. In this sense, sustaining sense of place faces the same concerns raised earlier in this paper about problems with sustainable forestry that fail to recognize competing objects of sustainability.

Traditional considerations of forest communities emphasize the promotion of "stability," but community "resilience" (the ability to change or adapt to changing circumstances) is another potential metaphor of community sustainability. Sense of place is an inherently change-aversive construct, oriented towards preserving established meanings against rapid social change. This orientation is reflected, for example, in calls 
to preserve logging "as a way of life," suggesting a defense of the views of the "old-timers" against those of "newcomers," of "locals" versus "outsiders." In this view, established place meanings are often considered more valid and important than ones which challenge them. This orientation towards "preserving meanings" reflects notions of community stability rather than community resilience. This may be problematic for sustainability if adhered to too strongly - there is a temptation to over-romanticize existing senses of place and marginalize voices that challenge them (e.g., Fortmann and Kusel 1990).

An alternative vision of sense of place under the umbrella of community resilience might address a range of place meanings (each presumably with strong attachments), rather than a dominant sense of place that must be conserved. Community sustainability may therefore be related to sociocultural diversity (Munasinghe and McNeely 1995) and communities with a diversity of place meanings may be more resilient and adaptable to social change.

\section{The Limitations of Subjective Measures}

Just as it is a poor idea to neglect the role of human concerns in forested systems, it is risky to depend entirely on locally defined sense of place results as the sole indicators of whether a human community is being sustained. One needs to temper enthusiasm about the advantages of local control (e.g., Audriac 1997) by acknowledging that community residents may be wrong about some things. Relying too heavily on subjective measures of well-being neglects potential impacts of ways of life that community residents either do not notice, or notice but are not concerned with. In short, local residents do not always know best. They may miss the connections between the style of life that supports community satisfaction and (for example) ecological impacts, or distribution within and between generations. This latter concern underscores the need for integrating subjective measures such as sense of place with other variables, especially those that address the maintenance of ecological integrity.

\section{Conclusion - The Utility of Sense of Place as an Indicator of Sustainability}

This paper has summarized the breadth of research approaches that have examined the sustainability of forest communities. The earliest characterization of the relationship between forests and people suggested that forests existed primarily to serve human needs. An expanded view of forestry maintains that forests should sustain ecological integrity, with humans as potential barriers to, rather than part of, forest sustainability. This paper has taken the position that sustainable forests must sustain human communities that depend on them. However, economic well-being (a traditional focus of research on the relationship between humans and forests) ought not to be the only focus. Non-economic indicators need to be assessed as well, including "subjective" indicators that reflect the perspective of community residents, rather than just the researcher. Subjective indicators can still be measured quantitatively in particular, addressing community sustainability via sense of place is advocated.

Sense of place, although not without problems of its own, measures up quite well to the criteria for social indicators delineated by Andrews and Withey (1976). Sense of place as an overall attitude towards a community (as well as the beliefs that compose them) can be measured statistically, monitored over time and compared between different community stakeholders. Because the belief component should reflect dominant issues of the community, sense of place is certainly relevant to policy. Sense of place also achieves the seemingly contradictory mandates of being "limited" to foster communication (perhaps as simple as an overall evaluative statement about how strongly one likes or dislikes one's community), but comprehensive (in that overall evaluations are composed of multiple beliefs and evaluations that should reflect the range of interests found there). Because they need to be collected through primary research, they can be disaggregated to whatever level of analysis the data collection procedure allows. The distribution of a community's place meanings and attachments among different groups of residents can also be assessed, providing insights into the nature of the distribution of social wellbeing.

\section{References}

Andrews, F.M. and S.B. Withey. 1976. Social Indicators of WellBeing. Plenum Press, New York.

Aplet, G.H., N. Johnson, J.T. Olson and V.A. Sample. 1993. Defining Sustainable Forestry. Island Press, Washington, DC.

Audriac, I. 1997. Rural sustainable development: a postmodern alternative. In I. Audriac (ed.). Rural Sustainable Development in America. pp. 3-24. John Wiley and Sons, New York.

Azar, C., J. Holmberg and K. Lindgren. 1996. Socio-ecological indicators for sustainability. Ecological Economics 18: 89-112.

Bateson, G. 1972. Steps to an Ecology of Mind. Chandler Publ., San Francisco, CA.

Campbell, A. 1981. The Sense of Well-Being in America: Recent Patterns and Trends. McGraw Hill, New York.

Campbell, A. and P.E. Converse. 1972. The Human Meaning of Social Change. Russell Sage Foundation, New York.

Carpenter, R.A. 1995. Limitations in measuring sustainability. In M. Munasinghe and J. McNeely (eds.). Defining and Measuring Sustainability. pp. 432-440. United Nations University and the World Bank, Washington, DC.

Drielsma, J.H. 1984. The Influence of Forest-Based Industries on Rural Communities. Yale Univ. Dissertation. Univ. Dissertation Services, Ann Arbor, MI.

Fisher, D.R. and D.S. Liebl. 1997. Analyzing indicators of sustainability as a tool for community needs assessment: the case of the Rock River basin. Unpubl. manuscript.

Fortmann, L. and J. Kusel. 1990. New voices, old beliefs: forest environmentalism among new and long-standing residents. Rural Sociology 55(2): 214-232.

Franklin, J.F. 1995. Sustainability of managed temperate forest ecosystems. In M. Munasinghe and J. McNeely (eds.). Defining and Measuring Sustainability. pp. 355-388. United Nations University and the World Bank, Washington, DC.

Gale, R.P. and S.M. Cordray. 1994. Making sense of sustainability: Nine answers to "what should be sustained?". Rural Sociology 59(2): 311-332.

Grieder, T. and L. Garkovich. 1994. Landscapes: the social construction of nature and the environment. Rural Sociology 59(1): 1-24. Heberlein, T.A., R.C Stedman, G.V. Fuguitt, R.M. Gibson and P.R. Voss. 1994. Forest dependence and community well being in the Pacific Northwest. Paper presented at The Annual Meetings of the Rural Sociological Society, Portland Oregon, Aug 12-14.

Hibbard, M. and J. Elias. 1993. The failure of sustained-yield forestry and the decline of the flannel-shirt frontier. In T.A. Lyson and W.W. Falk (eds.). Forgotten Places: Uneven Development in Rural America. pp. 195-217. University of Kansas Press, Lawrence, KS. Howze, G., C. Bailey, J. Bliss and L. Teeter. 1993. Regional 
comparisons of timber dependency in the Northwest and the Southeast. Paper presented at The Annual Meetings of the Rural Sociological Society, Orlando, Florida, Aug 7-10.

Johnson, N. 1993. Introduction. In G.H. Aplet, N, Johnson, J.T. Olson, and V.A. Sample. (eds.). Defining Sustainable Forestry. pp. 11-16. Island Press, Washington, DC.

Jorgensen, B.J. and R.C. Stedman. 1999. Measuring sense of place: lakeshore property owners' attitudes towards their properties. Paper under review at Journal of Environmental Psychology.

Kaufman, H.F. and L.C. Kaufman. 1946. Toward the Stabilization and Enrichment of a Forest Community: the Montana Study. USFS Region 1. Univ.of Montana, Missoula, MT

Kusel, J. 1996. Well-being in forest-dependent communities, part I: a new approach. Sierra Nevada Ecosystem Project: Final Report to Congress, Vol II: Assessments and Scientific Basis for Management Options. Univ. of California Centers for Water and Wildland Resources, Davis, CA.

Kusel, J and L. Fortmann. 1991. Well-being in forest-dependent communities. Vol I. California Department of Forestry, Forest and Rangeland Assessment Program, Sacremento, CA.

MacKaye, B. 1919. Employment and Natural Resources. Dept. Of Labor, Washington, D. (Cf Hibbard and Elias 1993).

Moum, T. 1988. Yea-saying and mood-of-the day effects in self-reported quality of life. Social Indicators Research 20(2): 108-125.

Munasinghe, M. and J. McNeely. 1995. Key concepts and terminology of sustainable development. In M. Munasinghe and J. McNeely (eds.). Defining and Measuring Sustainability. pp 19-56. United Nations University and the World Bank, Washington, DC. Munasinghe, M. and W. Shearer. 1995. An introduction to the definition and measurement of biogeophysical sustainability. In M. Munasinghe and J. McNeely (eds.). Defining and Measuring Sustainability. pp xvii-xxxii. United Nations University and the World Bank, Washington, DC.
Overdevest C. and G.P. Green. 1994. Forest dependency and community well-being: a segmented market approach. Society and Natural Resources 8: 111-131.

Rees, W.E. 1997. Ecological footprints and the imperative of rural sustainability. In I. Audriac (ed.). Rural Sustainable Development in America. pp. 3-24. John Wiley and Sons, New York.

Rivlin, A.M. 1993. Values, institutions, and sustainable forestry. In G.H. Aplet, N. Johnson, J.T. Olson, and V.A. Sample. (eds.). Defining Sustainable Forestry. pp. 255-259. Island Press, Washington, DC. Sample, V.A. 1993. Introduction - social and policy considerations in defining sustainable forestry. In G.H. Aplet, N. Johnson, J.T. Olson, and V.A. Sample. (eds.). Defining Sustainable Forestry. pp. 247-254. Island Press, Washington, DC.

Sen, A. 1984. Resources, Values, and Development. Harvard Univ. Press, Cambridge, MA.

Stedman, R.C. 1997. Where the north begins: cognitive maps, sense of place, and place attachment. Paper presented at The Annual Meetings of the Rural Sociological Society, Toronto, Ontario, Aug 13-17.

Toman, M.A. 1992. The Difficulty in Measuring Sustainability. Resources (Winter): 3-6.

World Commission on Environment and Development. 1987. Our Common Future. Oxford Univ. Press, Oxford. (generally referred to as the Brundtland Commission). 